\title{
AN ANALYSIS OF THE SOCIAL CONTEXT OF CHILDREN'S WEEKEND DISCRETIONARY ACTIVITY PARTICIPATION
}

\author{
Ipek N. Sener \\ The University of Texas at Austin \\ Department of Civil, Architectural \& Environmental Engineering \\ 1 University Station, C1761, Austin, TX 78712-0278 \\ Phone: (512) 471-4535, Fax: (512) 475-8744 \\ Email: ipek@mail.utexas.edu
}

\author{
Chandra R. Bhat* \\ The University of Texas at Austin \\ Department of Civil, Architectural \& Environmental Engineering \\ 1 University Station, C1761, Austin, TX 78712-0278 \\ Phone: (512) 471-4535, Fax: (512) 475-8744 \\ Email: bhat@mail.utexas.edu \\ *corresponding author
}


Sener and Bhat

\section{ABSTRACT}

This paper examines the discretionary time-use of children, including the social context of children's participations. Specifically, the paper examines participation and time investment in in-home leisure as well as five different types of out-of-home discretionary activities: (1) shopping, (2) social, (3) meals, (4) passive recreation (i.e., physically inactive recreation, such as going to the movies or a concert), and (5) active recreation (i.e., physically active recreation, such as playing tennis or running). The social context of children's activity participation is also examined by focusing on the accompanying individuals in children's activity engagement. The accompanying arrangement is classified into one of six categories: (1) alone, (2) with mother and no one else, (3) with father and no one else, (4) with both mother and father, and no one else, (5) with other individuals, but no parents, and (6) with other individuals and one or both parents. The utility-theoretic Multiple Discrete-Continuous Extreme Value (MDCEV) is employed to model time-use in one or more activity purpose-company type combinations.

The data used in the analysis is drawn from the 2002 Child Development Supplement (CDS) to the U.S. Panel Study Income Dynamics (PSID). The results from the model can be used to examine the time-use choices of children, as well as to assess the potential impacts of urban and societal policies on children's activity participation and time use decisions. Our findings also emphasize the need to collect, in future travel surveys, more extensive and higher quality data capturing the intra- and inter-household interactions between individuals (including children). To our knowledge, the research in this paper is the first transportation-related study to rigorously and comprehensively analyze the social dimension of children's activity participation.

Keywords: Children's discretionary activity, children's time use, multiple discrete continuous models, weekend travel, activity-based travel analysis. 


\section{INTRODUCTION}

\subsection{Background}

Activity-based travel methodologies focus on the time-use decisions of individuals, along with the spatial, temporal, and social contexts of activity episode participation (Bhat and Koppelman, 1999, Pendyala and Goulias, 2002). Several earlier activity studies have examined overall timeuse, and the spatial and temporal contexts of activity episode participation (see Arentze and Timmermans, 2004 and Bhat and Pendyala, 2005). However, the social context has received relatively scant attention in the activity analysis literature, as indicated by Axhausen (2005) and Goulias and Kim (2005). Specifically, there has been relatively limited research on the interactions of individuals with other household members and/or non-household members (i.e., inter-individual interactions) in the generation and scheduling of activity travel patterns (Srinivasan and Bhat, 2005).

The limited attention on inter-individual interactions has been somewhat alleviated by some recent studies emphasizing the need to recognize these interactions for accurate travel forecasting and transportation policy analysis (see Golob and McNally, 1997, Scott and Kanaroglou, 2002, Zhang et al., 2004, Bradley and Vovsha, 2005, Gliebe and Koppelman, 2005, Pribyl and Goulias, 2005, Srinivasan and Bhat, 2005, Srinivasan and Athuru, 2005, Kato and Mataumoto, 2006). But these earlier studies have focused on the interactions between the activity patterns of adults within the household. On the other hand, descriptive analyses suggest that there are substantial inter-household interactions in individual activity generation and scheduling (see Goulias and Kim, 2005, Srinivasan and Bhat, 2006a, and Copperman and Bhat, 2007a). Also, the overriding emphasis of earlier intra-household linkage studies is on adult activity-travel patterns. These studies have not explicitly considered the activity patterns of children, and the interactions of children's patterns with those of adults' patterns. If the activity participation of children with adults is primarily driven by the activity participation needs/responsibilities of adults (such as a parent having to go to the groceries, and tagging along her/his child for the grocery trip), then the emphasis on adults' activity-travel patterns would be appropriate. However, in many instances, it is the children's activity participations, and the dependency of children on adults for facilitating the participations, that lead to interactions between adults' and children's activity-travel patterns. For example, in the case of a parent dropping off a child at soccer practice, it is not the parent's activity but the child's activity, and its location, that determine the temporal and spatial 
dimensions of the trip (see Kitamura, 1983). Further, the dimension of "who" is involved in facilitating the child's activity participation determines which adult's activity-travel pattern is impacted (see Goulias and Kim, 2005). Of course, in addition to serving the participations of children, interactions between children's activity-travel patterns and adults' activity-travel patterns can also develop in the form of joint, mutually desirous, activity participations in shopping, going to the park, walking together, and other social-recreational pursuits.

The existence of interactions between children's activity-travel patterns and those of adults should be obvious from the above discussion. What is less obvious is how to capture these interaction effects. One approach, along traditional lines, would be to focus on adult activitytravel patterns, and use the presence, number, and age distribution of children in the household as determinant variables (among other variables) to model the time each adult in a family spends with each child in each of several activity purposes. These time investments can then form a skeleton for further detailed scheduling of the activities and travel of adults and children. This approach is consistent with the notion that it is the adults who decide on their children's activity participations, and schedule their own activity-travel patterns to accommodate those of their children. For instance, in the soccer example provided earlier, a parent may be the one who wants her/his son to partake in soccer and so schedules things in combination with other adults in the household (or even other adults outside the household) to facilitate this participation. The second approach to capture children-adult interaction effects is to focus on children's activitytravel patterns, and use adult demographic variables (among other variables) as determinant variables to model the time each child spends with adults in each of several activity purposes. These time investments, as earlier, can then form a skeleton for further detailed scheduling of the activities and travel of adults and children. This second approach recognizes that children as young as 6-8 years start developing their own identities and individualities, and social needs (see Stefan and Hunt, 2006, CDC, 2005, Eccles, 1999). They then interact with their parents and other adults to facilitate these needs.

In reality, there is likely to be a combination of adult decision-driven children activities as well as child decision-driven adult activities leading up to the interactions between children and adult activity-travel patterns. This suggests some kind of a hybrid strategy of the two approaches discussed earlier. But the activity-travel field is in its infancy in its understanding of children-adult interactions, leave alone determining what a hybrid strategy may be. The focus of 
this paper is to shed more light on children-adult linkages, so that future efforts can build on this research to examine realistic hybrid strategies. In doing so, we adopt the second "child-centric" approach in the paper. There are two main reasons for using such an approach. First, we are interested in children's activity-travel patterns (regardless of who makes the decisions), as opposed to the dominant focus on adult activity-travel patterns in extant activity-based research. In analyzing children's activity-travel patterns, it is easier to work directly with children as the unit of analysis. Second, few data collection efforts have obtained information that allows a study of the interactions of adults and children in activity-travel decision-making. The 2002 Child Development Supplement (CDS) to the Panel Study of Income Dynamics (PSID) is an exception. This survey effort obtained detailed information on all aspects of both in-home and out-of-home activity participation of a sample of about 2500 children from sampled households. The data explicitly collected information on all persons (both households and non-households members) accompanying the respondent for each activity episode. In using this rich dataset, a child-centric approach needs to be adopted.

\subsection{The Current Study}

The discussion in the previous section motivates the current study. Our overall objective is to contribute toward a better understanding and modeling of the activity participation of children (aged 15 years or younger). More specifically, we emphasize the social context of children's participations, focusing on the time investment of children in various activity purposes with each of several possible accompanying person(s). ${ }^{1}$ The accompanying arrangement is classified into one of the following six categories: (1) alone, (2) with mother and no one else, (3) with father and no one else, (4) with both mother and father, and no one else, (5) with other individuals, but no parents, and (6) with other individuals and one or both parents.

In the current modeling effort, we confine our attention to the discretionary (leisure) activity participation of children over the weekend days. The emphasis on discretionary participation is because there is much more variety in the accompaniment type for discretionary activity purposes than for non-discretionary purposes (see Copperman and Bhat, 2007a). The focus on weekend days is because children participate in discretionary activities at much higher

\footnotetext{
${ }^{1}$ As indicated in the previous section, these time investments in activity purposes with each possible accompanying person(s) can then form the basis for detailed activity episode participation and scheduling.
} 
levels, and for substantially longer durations, on weekend days compared to weekdays (Stefan and Hunt, 2005). There is also much more of joint activity participation of children with others during the weekends than weekdays (Copperman and Bhat, 2007a). ${ }^{2}$

The accompanying arrangement and other contexts of children's weekend discretionary activity participations are likely to vary based on the discretionary activity purpose, as indicated by Copperman and Bhat, 2007a. Thus, in this paper, we disaggregated discretionary activities into five purposes: (1) non-grocery shopping, (2) social, (3) meals, (4) passive recreation (such as going to the movies/concerts, attending sports events, and arts and crafts), and (5) active recreation (such as sports, games, and physical play).

The current analysis, while motivated from an activity-based travel analysis standpoint, also contributes to the sociological and public health literatures. From a sociological perspective, studies have found that providing opportunities for, and facilitating participation in, certain forms of discretionary activity pursuits aids the emotional well-being and mental health of children, reduces the incidence of drug and tobacco use, and helps children develop social skills, teamwork abilities, fairness concepts, and tolerance (see, for example, Hofferth and Sandberg, 2001, United Nations, 2000, Larson and Verma, 1999). Also, the analysis of accompaniment type, and particularly parental involvement, in children's activity participation is a topic of substantial interest in the sociological and developmental psychology fields in the context of children's achievement success, sense of responsibility, and work ethic (see Bianchi and Robinson, 1997, Sandberg and Hofferth, 2001, Shann, 2001, Hofferth and Jankuniene, 2001). From a public health standpoint, an analysis of the time use of children in passive and active discretionary activities contributes to efforts directed toward promoting the health of children, an issue gaining substantial interest at the interface of the transportation and public health fields (see CDC, 2006, Transportation Research Board and Institute of Medicine, 2005, Copperman and Bhat, 2007a, Bhat and Gossen, 2004).

\footnotetext{
${ }^{2}$ In addition to the specific need to focus on weekends in the context of children's discretionary activity participation and the social context of children's participations, there is an increasing recognition of the general need to examine weekend activities and travel in activity-travel analysis. This is because the total volume of travel, and total person miles of travel, undertaken during weekdays and weekend days are comparable (see Parsons Brinckerhoff Quade and Douglas, 2000, and Lockwood et al., 2005). Additionally, the differences between weekdays and weekend days, especially in the temporal profiles of the travel patterns, have implications for air quality modeling. The sustained high volume of weekend trips during the hotter (i.e., mid-day) period of the day can amplify the severity of the impact of emissions on air quality. The longer soak times of vehicles prior to first use during weekends (as a consequence of departure from home much later in the day) compared to weekdays can also increase air pollution from emissions.
} 
The formulation used in the current analysis is Bhat's multiple discrete-continuous extreme value (MDCEV) model (Bhat, 2005, Bhat 2007). This model is used to examine the factors impacting children's time-use in 31 activity purpose-accompaniment type combinations, corresponding to the combinations of 5 discretionary activity purposes and 6 accompaniment types for out-of-home activities (= 30 alternatives), and a combined in-home discretionary activity category. All children participate for some amount of time in the in-home discretionary activity category, and this category constitutes the "outside" good in the MDCEV model. ${ }^{3}$ The focus of the model then is on daily participation (discrete component of whether the child participates) and participation duration (continuous component) choices of children in each of the 30 out-of-home discretionary type-accompaniment type categories.

The MDCEV model is ideally suited for such an analysis because it is a utility-theoretic formulation that accommodates participation in multiple discretionary type-accompaniment type categories on the same weekend day. ${ }^{4}$ The MDCEV model uses a non-linear, additive, utility structure that is based on diminishing marginal utility (or satiation effects) with increasing participation duration in any alternative. That is, it is assumed that each of the discretionary activity categories represent "goods" that, when consumed (i.e., invested in in terms of time) provide positive utility. However, the marginal utility of time investment in any discretionary activity purpose diminishes with increasing time invested in that activity. The model also accommodates zero participation in one or more out-of-home discretionary categories.

The rest of the paper is structured as follows. The next section presents the data source and discusses the sample formation procedure. This section also provides important descriptive statistics of the sample. Section 3 provides an overview of the model structure and describes the estimation procedure. Section 4 presents the empirical analysis results. Finally, Section 5 summarizes the major results from the study, evaluates the value of the model with possible implications, and concludes the paper.

\footnotetext{
${ }^{3}$ The term "outside good" refers to a good that is "outside" the purview of the choice of whether to be consumed or not. That is, the "outside good" is a good that is always consumed by all consumers.

${ }^{4}$ A utility-theoretic formulation, as used here, is one that derives its theoretical basis in microeconomic utility concepts of consumer choice.
} 


\section{DATA SOURCE AND SAMPLE FORMATION}

\subsection{Data Source}

The main data source for this analysis is the 2002 Child Development Supplement (CDS) to the Panel Study of Income Dynamics (PSID). The PSID is a longitudinal study of a representative sample of U.S. households (men, women, and children) that has collected, since 1968, detailed demographic, employment, and health data.

The 2002 CDS obtained information from over 2500 children aged 18 years or younger from a portion of the PSID sampled households. The CDS included health and achievement test information, primary caregiver and child interviews, and a two-day time use diary - one for a weekday and another for a weekend day. The time use paper diaries were mailed to children with a request to be filled out on or around the designated survey day for the child. Instructions were provided for the diary to be filled by the targeted child, whenever possible. Older children and adolescents were expected to fill out their own diary, while primary caregivers aided younger children. The diaries were then retrieved and reviewed by an interviewer either by phone or in person.

The time-use diaries collected information on the complete sequence of in-home and out-of-home activity episodes undertaken by the child for each designated weekday and weekend day beginning at midnight. Each activity episode was characterized by when it began and ended,

whether any other activity was taking place simultaneously, the location of participation, and with whom the episode was pursued.

\subsection{Sample Formation}

Several steps were pursued in extracting the final sample for analysis. First, only individuals aged 15 years or younger were considered in the analysis to restrict the sample to those who cannot independently drive themselves to out-of-home activities. Second, only children living with one or both parents were selected from the original pool of children. Third, the weekend day of survey was selected for each child, since the focus of the current analysis is exclusively on weekend days. Fourth, all activity episodes in which children participated were classified as inhome or out-of-home, according to the location of the activity episode participation. Fifth, all activity episodes were categorized by purpose and only the discretionary activity episodes were chosen for this study. Sixth, all out-of-home discretionary activity episodes were classified into 
one of the following categories: shopping (other than grocery shopping), social activities (such as visiting, attending club meetings, conversation, and parties), meals, passive recreation (such as unorganized hobbies, attending sports events, going to the movies/concerts, and arts and crafts), and active recreation (sports, games, and physically active play). Seventh, in-home discretionary activity episodes were all aggregated into a single in-home discretionary activity purpose category. At the end (of this purpose classification), there are 6 discretionary activity purpose categories: (1) in-home discretionary (or IH leisure for short), (2) out-of-home non-grocery shopping (shopping), (3) out-of-home social (social), (4) out-of-home meals (meals), (5) out-ofhome passive recreation (passive recreation), and (6) out-of-home active recreation (active recreation). In the rest of the paper, we will use the short form for the activity purposes, as identified in parentheses just above. Next, in the eighth step, activity episodes were classified based on accompaniment type: (1) alone, (2) with mother and no one else (mother), (3) with father and no one else (father), (4) with both mother and father, and no one else (parents), (5) with other individuals, but no parents (no parents), and (6) with other individuals and one or both parents (parents and others). Again, we will use the short form for accompaniment type in the rest of this paper. Finally, episodes were classified into 31 activity purpose-accompaniment type categories (30 out-of-home categories plus one in-home category), and the time investments across all episodes in the day within each category were aggregated to obtain total daily time investments in each of the categories. The participation decisions, and the daily time investments, in the 31 categories constitute the dependent variables for the MDCEV model. ${ }^{5}$

\subsection{Descriptive Time-Use Statistics in Sample}

The final sample considered in this analysis includes the weekend day time-use information of 1574 children aged 5-15 years. Each child in the sample contributes only one weekend day, with 800 children providing time-use diaries on Saturday, and 774 children on Sunday. Table 1 presents the descriptive statistics of participation in each of the activity purposes defined in our study. The first row indicates that all children participate during the weekend day in IH leisure (see the second column of the table). As indicated in Section 1.2, the in-home leisure activity category serves as the "outside good" in our analysis. The mean duration of participation in IH

\footnotetext{
${ }^{5}$ The reader will note that IH leisure was retained as a single category, without breaking it down by accompaniment type. This is because the accompanying arrangement for in-home episodes can be expected to be less structured and more spontaneous than for out-of-home episodes.
} 
leisure is rather high (457 minutes or about 7.5 hours; see third column under IH leisure). Among the out-of-home discretionary activity categories, about half of the children participate in social and passive recreation activities. Participation levels in shopping, meals, and active recreation are lower than in social and passive recreation. Also, when participated in, the time investments in passive recreation and active recreation are high, while that in meals is very low. Overall, these observations indicate the low baseline preference and high satiation rates for the out-ofhome $(\mathrm{OH})$ activity purposes relative to $\mathrm{IH}$ leisure. Among the $\mathrm{OH}$ discretionary purposes, there is a higher baseline preference for social and passive recreation than other purposes, and a higher satiation for shopping, social, and meals relative to passive and active recreation.

The last two columns in Table 1 present the split between solo participations (i.e., participation in only one discretionary activity category) and multiple activity participations (i.e., participation in multiple discretionary activity categories) for each activity type. The results in the first row show that $4 \%$ of children (68 out of 1574) participate only in IH leisure activity during weekend days and that 1506 (96\%) participate in IH leisure along with the participation in one or more of the out-of-home discretionary activity purposes. For the out-of-home activity purposes, the solo and multiple activity participation figures are computed without considering IH leisure. Thus, the figures for shopping indicate that 115 of the 533 (22\%) children participate in shopping and no other $\mathrm{OH}$ discretionary activity purpose, while 418 (78\%) participate in shopping along with one or more $\mathrm{OH}$ purposes. Overall, these last two columns of Table 1 show the high prevalence of participation in multiple discretionary activity purposes over the weekend day, highlighting the need for, and appropriateness of, the MDCEV model.

Table 2 provides the descriptive statistics of accompaniment type for the out-of-home discretionary activity participation of children. From the second column in the table, it can be observed that a high percentage of children undertake out-of-home discretionary activities with no parents $(65 \%)$, and with parents and others $(51 \%) .{ }^{6}$ The third column in Table 2 indicates that time investment in activities with no parents has the highest mean duration (about 3 hours). This suggests a high preference and a low satiation for out-of-home discretionary activities

\footnotetext{
${ }^{6}$ While not shown explicitly in Table 2 due to space constraints, there are variations in the accompaniment type by age of the child. An analysis segmenting children who participate in out-of-home discretionary activity into those 10 years or less and those above 10 years of age indicated that the older children are more likely to participate with no parents around (70\% for older children versus $62 \%$ for the younger children) and less likely to participate with parents and others ( $41 \%$ for older children versus $59 \%$ for the younger children). Interestingly, however, there were no substantial differences in participation rates between the age groups in the "alone", "mother", "father", and "parents" accompaniment categories.
} 
undertaken with no parents over weekend days. The results also indicate the low baseline preference (i.e., low participation level) and high satiation (i.e., low durations) when children are accompanied with both their mother and father, and no one else. The final two columns of Table 2 indicate the presence of very high levels of combinations of companionship types for children's weekend day out-of-home discretionary activity participation, particularly when children participate alone or with one or both parents (see the high percentages in the first four rows of the last column of the Table).

In the current analysis, we focus on the interactions of activity type and companionship type. Tables 1 and 2, on the other hand, only show the distributions along each of the activity purpose and companionship type dimensions. In Table 3, we present the participation levels in out-of-home discretionary pursuits by activity purpose and company type. The unidimensional participation statistics are reproduced in the first two number columns (for activity purpose) and the first number row (for company type). The remainder of the rows and columns provide the descriptive statistics on the combination categories. Thus, the entries in the "shopping alone" cell indicate that 24 individuals (4.5\% of all children participating in shopping) participate in shopping activity alone (note that the percentages for each row across company types sum to more than $100 \%$ because of multiple discreteness; for instance, a child can participate in shopping activity episodes alone and with the mother on a given day). The results show that children are more likely to participate in shopping with one or both parents (especially with the mother) than in other activity purposes (the exception is that children are as likely to participate with both parents in meals as in shopping). Additionally, a higher percentage of children participate alone in passive recreation than in other activity purposes. Children also participate in social, passive, and active recreation purposes with no parent around to a much higher extent than in shopping and meals. ${ }^{7}$

\section{THE MDCEV MODEL}

In this section, we present an overview of the MDCEV model structure, which is used to examine children's daily participation, and time investment, in each activity purpose-company

\footnotetext{
${ }^{7}$ These trends apply to both younger and older children. Also, older children are consistently more likely to participate with no parents across all activity purposes, and less likely to participate with parents and others across all activity purposes. Older children are more likely than younger children to participate alone in shopping, active recreation, and meal activities.
} 
type combination. The reader is referred to Bhat (2005) and Bhat (2007) for the intricate details of the model structure.

\subsection{Basic Structure}

Designate the first alternative as the IH leisure category, which is also the outside good that is always consumed. The rest of the $(K-1)$ alternatives correspond to the out-of-home discretionary activity purpose-companionship type combinations (30 such combinations in the current analysis, for a total of 31 alternatives). Consider the following additive utility function form ${ }^{8}$ :

$$
U(\boldsymbol{t})=\frac{1}{\alpha_{1}} \exp \left(\varepsilon_{1}\right) t_{1}^{\alpha_{1}}+\sum_{k=2}^{K} \gamma_{k} \exp \left(\beta^{\prime} z_{k}+\varepsilon_{k}\right) \ln \left(\frac{t_{k}}{\gamma_{k}}+1\right)
$$

In the above utility function, $\boldsymbol{t}$ is the vector of time investments $\left(t_{1}, t_{2}, \ldots, t_{k}\right)$, or equivalently, the time spent on the activity purpose-companion type combinations. ${ }^{9} z_{k}$ in Equation (1) is a vector of exogenous determinants (including a constant) specific to alternative $k$ (there is no such vector for the first alternative because only differences in utilities matter, as shown later). The term $\exp \left(\beta^{\prime} z_{k}+\varepsilon_{k}\right)$ is the marginal random utility of one unit of time investment in alternative $k$ at the point of zero time investment for the alternative (as can be observed by computing $\left.\partial U(\boldsymbol{t}) /\left.\partial t_{k}\right|_{t_{k}=0}\right)$. Thus $\exp \left(\beta^{\prime} z_{k}+\varepsilon_{k}\right)$ controls the discrete choice participation decision in alternative $k$. We will refer to this term as the baseline preference for utility $k$. The term $\gamma_{k}$ is a translation parameter that serves to allow corner solutions (zero consumption) for the "inside" alternatives $k=2,3, \ldots, K\left(\gamma_{k}>0\right)$. However, it also serves as a satiation parameter for these inside alternatives - values of $\gamma_{k}$ closer to zero imply higher satiation (or lower time investment) for a given level of baseline preference (see Bhat, 2007). There is no $\gamma_{1}$ term for the first alternative because it is always consumed. However, satiation

\footnotetext{
${ }^{8}$ Some other utility function forms were also considered, but the one below provided the best data fit. For conciseness, we do not discuss these alternative forms. The reader is referred to Bhat (2007) for a detailed discussion of alternative utility forms. The reader will also note the implicit assumption in the formulation below that there is utility gained from investing time in discretionary activities. This is a reasonable assumption since individuals have the choice not to participate in such activities.

${ }^{9}$ The individual has the vector $\boldsymbol{t}$ as the decision vector. The second through $K^{\text {th }}$ elements of $\boldsymbol{t}$ can either be zero or some positive value (the first element of $\boldsymbol{t}$ should be positive). Whether or not a specific $t_{k}$ value $(k=2,3, \ldots, K)$ is zero constitutes the discrete choice component, while the magnitude of each non-zero $t_{k}$ value constitutes the continuous choice component.
} 
effects in alternative 1 are captured through the exponential $\alpha_{1}$ parameter $\left(\alpha_{1} \leq 1\right.$, so that marginal utility decreases with increasing time investment in IH leisure). The constraint that $\alpha_{1} \leq 1$ is maintained by reparameterizing $\alpha_{1}$ as $1-\exp \left(\theta_{1}^{\prime} y_{1}\right)$, where $y_{1}$ is a vector of childassociated characteristics (including a constant) impacting $\alpha_{1}$, and $\theta_{1}$ is a vector to be estimated. Similarly, the constraint that $\gamma_{k}>0$ for $k=2,3, \ldots, K$ is maintained by reparameterizing $\gamma_{k}$ as $\exp \left(\lambda_{k}{ }^{\prime} \omega_{k}\right)$, where $\omega_{k}$ is a vector of child-related characteristics and $\lambda_{k}$ is a vector to be estimated.

From the analyst's perspective, individuals are maximizing random utility $U(t)$ subject to the time budget constraint that $\sum_{k} t_{k}=T$, where $T$ is the total time available for children to participate in discretionary activity pursuits. The optimal time investments $t_{k}^{*}(k=1,2, \ldots, K)$ can be determined by forming the Lagrangian function (corresponding to the problem of maximizing utility $U(\boldsymbol{t})$ under the time budget constraint $T$ ) and applying the Kuhn-Tucker (KT) conditions. After extensive, but straightforward, algebraic manipulations, the KT conditions collapse to (see Bhat, 2007):

$$
\begin{aligned}
& V_{k}+\varepsilon_{k}=V_{1}+\varepsilon_{1} \text { if } t_{k}^{*}>0(k=2,3, \ldots, K) \\
& V_{k}+\varepsilon_{k}<V_{1}+\varepsilon_{1} \text { if } t_{k}^{*}=0(k=2,3, \ldots, K), \text { where } \\
& V_{1}=\left(\alpha_{1}-1\right) \ln t_{1}^{*}, \text { and } V_{k}=\beta^{\prime} z_{k}-\ln \left(\frac{t_{k}^{*}}{\gamma_{k}}+1\right)(k=2,3, \ldots, K)
\end{aligned}
$$

Assuming that the error terms $\varepsilon_{k}(k=1,2, \ldots, K)$ are independent and identically distributed across alternatives with a type 1 extreme value distribution, the probability that the child allocates time to the first $M$ of the $K$ alternatives (for duration $t_{1}^{*}$ in the first alternative, $t_{2}^{*}$ in the second, $\ldots t_{M}^{*}$ in the $M^{\text {th }}$ alternative) is (see Bhat, 2007):

$$
\begin{aligned}
& P\left(t_{1}^{*}, t_{2}^{*}, t_{3}^{*}, \ldots t_{M}^{*}, 0,0,0 . .0\right)= \\
& {\left[\prod_{i=1}^{M} c_{i}\right]\left[\sum_{i=1}^{M} \frac{1}{c_{i}}\right]\left[\frac{\prod_{i=1}^{M} e^{V_{i}}}{\sum_{k=1}^{K} e^{V_{k}}}\right](M-1) !, \text { where }}
\end{aligned}
$$




$$
c_{1}=\left(\frac{1-\alpha_{1}}{t_{1}^{*}}\right), \text { and } c_{i}=\left(\frac{1}{t_{i}^{*}+\gamma_{i}}\right) \text { for } i=2,3, \ldots, M
$$

\subsection{Mixed MDCEV Structure and Estimation}

The structure discussed thus far does not consider correlation among the error terms of the alternatives. On the other hand, it is possible that children who like to participate in a certain kind of out-of-home discretionary activity (such as, say, shopping) due to unobserved individual characteristics will participate more than their observationally-equivalent peers in all companion type arrangements involving that out-of-home discretionary activity. Similarly, it may be that certain children have an overall unobserved tendency to participate alone in activities (say, due to their socially introverted nature), and these children have a higher likelihood (than their observationally-equivalent peers) to participate alone in all activity purposes. Such error components can be accommodated by defining appropriate dummy variables in the $z_{k}$ vector to capture the desired error correlations, and considering the corresponding $\beta$ coefficients in the baseline preference of the MDCEV component as draws from a multivariate normal distribution. In general notation, let the vector $\beta$ be drawn from $\phi(\beta)$. Then the probability of the observed time investment $\left(t_{1}^{*}, t_{2}^{*}, \ldots t_{M}^{*}, 0,0, \ldots 0\right)$ for the child can be written as:

$$
P\left(t_{1}^{*}, t_{2}^{*}, \ldots t_{M}^{*}, 0,0,0 . .0\right)=\int_{\beta} P\left(t_{1}^{*}, t_{2}^{*}, . . t_{M}^{*}, 0,0, . .0 \mid \beta\right) \phi(\beta) d \beta,
$$

where $P\left(t_{1}^{*}, t_{2}^{*}, \ldots, t_{M}^{*}, 0,0, \ldots 0 \mid \beta\right)$ has the same form as in Equation (3).

The parameters to be estimated in Equation (4) include the $\beta$ vector, the $\theta_{1}$ vector embedded in the $\alpha_{1}$ scalar, the $\lambda_{k}$ vector embedded in the $\gamma_{k}$ scalar $(k=2,3, \ldots, K)$, and the $\sigma$ vector characterizing the covariance matrix of the error components embedded in the $\beta$ vector.

The likelihood function (4) includes a multivariate integral whose dimensionality is based on the number of error components in $\beta$. The parameters can be estimated using a maximum simulated likelihood approach. We used Halton draws in the current research for estimation (see Bhat, 2003). We tested the sensitivity of parameter estimates with different numbers of Halton draws per observation, and found the results to be very stable with as few as 100 draws. In this analysis we used 125 draws per child in the estimation. 


\section{EMPIRICAL ANALYSIS}

\subsection{Model Specification}

Several types of variables were considered as determinants of children's time investment in each of the many discretionary activity purpose-company type categories. These variables may be classified into five groups: (1) child demographics (age, sex, race, and physical limitations), (2) parents' demographics (age, education level, and employment status of mother and father), (3) household demographics (number of adults, number of children, household structure, and household income), (4) household location variables characterizing the neighborhood type (urban, suburban, or rural) and region of the U.S. (northeast, northcentral, west, and south), and (5) activity day variables (season of year and day of weekend). Several different variable specifications, and functional forms for variables (such as linear and non-linear age/income effects), were attempted. Different error components specifications were also considered to generate covariance patterns in the baseline preference of the MDCEV alternatives. The final specification was based on intuitive considerations, insights from previous literature, parsimony in specification, and statistical fit/significance considerations.

One important issue regarding the specification of the availability of alternatives is that the "mother" company type category is specified as not being available for single-parent families only with the father, and the "father" company type category is specified as not being available for single-parent families only with the mother. In all single-parent families, there is also no "parents" (i.e., both mother and father, and no one else) category. This is to recognize the different propensities to participate with one or both parents in single-parent and two-parent households. $^{10}$

\subsection{Empirical Results}

The final specification results of the mixed MDCEV model are provided in Table 4. The estimates presented in the table refer to the $\beta$ vector in Equation (1). The IH leisure alternative serves as the base category for most (but not all) variables. The results are presented so that the effect of each variable is first identified separately along the activity purpose and company type

\footnotetext{
${ }^{10}$ If a child in a single-mother (single-father) household participates in an activity with her/his father (mother) and no one else, this is classified under "with other individuals, but no parents (no parents)" category. If such a child participates with both parents, and no one else, this time investment is classified under the "parents and others" category.
} 
dimensions. The final row of the table identifies any interaction effects of each variable over and above the unidimensional effects. ${ }^{11}$

\subsubsection{Child Demographics}

Among the child demographic variables, the effects of child's age indicate that older children are less likely to participate in passive recreation than in the other discretionary activity purposes. They are also less likely to participate in out-of-home discretionary (OHD) activities with their mother, and combination of parents and others, than by themselves, with their father, or both parents together. As expected, older children are much more likely to participate in OHD activities without parents than are younger children, indicating a higher degree of independence in the decision making and activity participation of older children.

The table also shows several differences in discretionary activity patterns between a male child and a female child. Specifically, male children are less predisposed to participate in shopping, and more predisposed to active recreation pursuits, than are female children (see Kohl III and Hobbs, 1998 and Copperman and Bhat, 2007b, for similar results). The increased tendency of male children to participate in active recreation is particularly elevated for the case of participation with no parents (see the interaction term of active recreation with no parents at the bottom of the table). The effect of the male variable on the company type dimension shows gender preferences, with males less likely to participate with the mother, and males having a higher disposition to participate with the father.

The impacts of the child's race suggest that Caucasian-Americans and AfricanAmericans have a lower baseline preference for participation in shopping activities relative to the other races (Hispanic-American, Asian-American, mixed-race, etc.). In addition, the results indicate that, while Caucasian-Americans are more likely to participate in passive and active recreation, African-Americans are less likely to undertake meal activities (see Srinivasan and

\footnotetext{
${ }^{11}$ Thus, the alternative-specific coefficients for the variable "child's age" are (from the first number column of Table 4) as follows: IH leisure (0.000), shopping-alone (0.000), social-alone $(0.000)$, meals-alone $(0.000)$, passive recreation-alone (-0.821), active recreation-alone (0.000), shopping-mother (-0.827), social-mother (-0.827), mealsmother $(-0.827)$, passive recreation-mother $(-0.821-0.827=-1.648)$, active recreation-mother $(-0.827)$, shoppingfather $(0.000)$, social-father $(0.000)$, meals-father $(0.000)$, passive recreation-father $(-0.821)$, active recreation-father $(0.000)$, shopping-parents $(0.000)$, social-parents $(0.000)$, meals-parents $(0.000)$. passive recreation-parents $(-0.821)$, active recreation-parents (0.000), shopping-no parents (1.128), social-no parents (1.128), meals-no parents (1.128), passive recreation-no parents $(-0.821+1.128=0.307)$, active recreation-no parents (1.128), shopping-parents and others (-0.625), social-parents and others (-0.625), meals-parents and others $(-0.625)$, passive recreation-parents and others $(-0.821-0.625=-1.446)$, and active recreation-parents and others $(-0.625)$.
} 
Bhat, 2006b for similar race effects related to adult participation in out-of-home discretionary activities). These race-related differences need additional scrutiny, especially since they point to race-related differences in health-enhancing active recreation pursuits. The differences could be due to culture-related reasons and/or lack of adequate active recreation facilities in and around neighborhoods of specific segments of the population. The other race-related effects in Table 4 indicate the higher participation levels of Caucasian-American children with their mothers and with no parents in social/meal activities, and lower (higher) participation levels of AfricanAmerican children with their fathers (with no parents) (Cooksey and Fondell (1996) and Hofferth (2003) also observed the lower participation levels of children with their fathers in African-American households relative to the Caucasian-American households). Additional research is needed to examine these race effects.

Finally, children who are physically challenged tend not to participate with non-parents, presumably because of the dependence on parents to overcome their physical challenges in pursuing discretionary activities. It is indeed interesting, and comforting, that physically challenged children do not appear to be any more confined to IH leisure than their physically normal peers.

\subsubsection{Parent Demographics}

The age of the parents does not substantially impact the discretionary activity participation of children. The only marginally significant effects are increased participation levels in out-of-home discretionary pursuits with an older parent than with a younger parent. This is an interesting result, perhaps indicating more stability in lifestyles among older parents, and a conscious effort to spend time with children in such households to enhance children's emotional-psychological development.

The effects of the parental employment variables in Table 4 suggest that, in two-parent households with only the father employed, children are less likely to participate in out-of-home discretionary (OHD) activities with the mother on weekend days. This may be a manifestation of "saturation" effects in joint activity participation of the mother with the child (and vice versa) over the weekdays. A similar effect of the father participating less with the child on weekend days if only the mother was employed was observed, but this effect was statistically insignificant 
(perhaps due to the much fewer number of children in two-parent households with the mother working, but not the father).

The impacts of the education variables are rather interesting. Children in households with well educated mothers (Bachelor's degree or higher) are less likely to pursue shopping, and those in households with well educated fathers are more likely to pursue social activities. These results suggest a family environment in educated parent households that is more balanced than the gender-based stereotype of women inclined to shop and men shying away from social pursuits. The results also show that children with a well educated mother are more likely to participate in OHD activities with their mother (either alone or with others) than children with a not-so-highly educated mother. This may be attributed to a heightened awareness, among well educated mothers, of the importance of shared time with children (see Sandberg and Hofferth, 2001). Surprisingly, however, the increase in OHD activity participation of children with well educated mothers does not extend to participation in social activities. (Please see the negative sign on the variable "Bachelor's or more" belonging to the "social with mother" category in Table 4). It is also noteworthy that the father's education level does not have much of an impact on the child's discretionary activity pursuits.

\subsubsection{Household Demographics}

The household demographic effects in Table 4 show that children in households with a large number of adults are less likely to participate in passive recreation activities outside home, presumably due to increased opportunity to pursue such passive recreation activities inside home (see Bhat et al., 2006 for a similar result). Further, as may be expected, children in households with several adults participate less in OHD activities with both parents, and no one else.

The number of children in the household also has an impact on discretionary activity participation levels of a child. Specifically, the more the children in the household, the less is the likelihood to participate in meals and passive recreation (perhaps because of increased opportunities for interactions in-home with siblings, though this effect is not observed for the out-of-home pursuits of shopping, social, and active recreation categories). The results also show a decrease in parental involvement toward only one child when there are several children, a result of increased number of children to attend to and spend time with. However, as expected, 
there is a higher propensity of participation with parents and others (including siblings), as is manifested in the positive coefficient on the "parents and others" category.

In single-father families, children spend more time with the father than in two-parent households. However, there is no such difference in maternal involvement between singlemother and two-parent households. These results potentially reflect the increased initiative of the father in single-parent households to spend time with his children. However, mothers seem to spend time with their children in any arrangement, reinforcing their primary care-giving role (see Sandberg and Hofferth, 2001). As expected, children in single parent households pursue out-ofhome discretionary activities with non-parents more than children in other households, except for passive recreation pursuits.

Finally, among household demographics, children in low-income households (less than an annual income of $\$ 25,000$ ) participate more in in-home leisure than out-of-home discretionary activity pursuits, perhaps due to financial constraints (see Bhat et al., 2006 for similar incomerelated effects on out-of-home discretionary participation).

\subsubsection{Household Location Variables}

The impacts of zonal location characteristics show that children residing in urban areas have a higher baseline preference associated with shopping and active recreation pursuits relative to children residing in suburban and rural zones, presumably due to improved accessibility to activity locations in urban areas. Also, children residing in urban zones have a higher likelihood of participating alone in out-of-home discretionary activities, possibly a result of less "protectionism" on the part of urban parents and/or urban built environment characteristics that provide independent mobility opportunities to activity locations.

The region location variable effects suggest that, in general, children are more likely to participate in IH leisure activities if they reside in the northeast and north-central parts of the U.S. relative to the south and west parts of the U.S. This can be attributed to more extreme weather conditions in the northeast and north-central parts relative to the more temperate conditions in the south and west. The regional location effects also suggest less soloparticipations in out-of-home discretionary pursuits in the northeast and western of the U.S. ${ }^{12}$

\footnotetext{
${ }^{12}$ We also attempted interactions of season and region variables, but these did not turn out to be statistically
} significant. 


\subsubsection{Day of Week/Seasonal Effects}

Children participate more in IH leisure on Sundays than on Saturdays. This is consistent with several other studies indicating that Sundays serve the purpose of "rest" days at home before the transition to school the next day (see Bhat and Gossen, 2004 for a similar result in the context of adults' recreational activity participation). The high propensity to participate in social events on Sundays is directly related to church-related activities, which also contributes to the decreased likelihood of participating alone on Sundays.

The seasonal effects do not substantially impact discretionary activity participation characteristics, except for the decreased tendency to participate in active recreation pursuits, and an increased likelihood of participating with no parents, in the Fall and Winter seasons relative to the Spring and Summer seasons.

\subsubsection{Baseline Preference Constants}

The baseline preference constants (final part of Table 4) do not have any substantive interpretations. They capture generic tendencies to participate in each discretionary purposeaccompaniment type category as well as accommodate the range of the continuous independent variables in the model. However, all the baseline preference constants are negative, indicating the high participation level in IH leisure relative to the out-of-home discretionary activity categories.

\subsubsection{Satiation Parameters}

The satiation parameter, $\alpha_{1}$, for the outside good (i.e., in-home leisure activity), and the translation/satiation parameters $\gamma_{k}(k=2,3, \ldots, K)$ for the inside goods (i.e., the 30 out-of-home activity type-company type combinations), influence the length of participation in any alternative. The $\alpha_{1}$ parameter was estimated to be 0.338 with a t-statistic value of 23.07 (for the null hypothesis that $\alpha_{1}=1$ ). This clearly indicates satiation effects in the "consumption" of IH leisure (i.e., the marginal utility of $\mathrm{IH}$ leisure decreases with increasing time investment in $\mathrm{IH}$ 
leisure). ${ }^{13}$ The $\gamma$ parameters for the out-of-home activity type-company type combinations are presented in Table 5. ${ }^{14}$ The $\gamma$ parameters indicate, in general, low satiation for the passive and active recreation categories (notice that the $\gamma$ values are on the high side for these categories), and high satiation effect for the shopping and meals categories (the $\gamma$ values are closer to zero for these categories). However, there are variations within each activity purpose based on company type. For instance, the duration of social activity time investment tends to be lower (i.e., higher satiation) for participation with the father compared to participation with other company types (the $\gamma$ parameter is 0.182 for "social with father" compared to a value of around 0.3 to 0.4 for social activities with other company types). Overall, the results indicate significant variations in time investment based on activity purpose and company type.

\subsubsection{Error Components}

The final specification included two error components - one specific to the activity dimension, and the other specific to the company type dimension (see Section 3.2). The activity dimension error component had a standard deviation of 0.183 (with t-statistics of 1.520), and the companytype error component had a standard deviation of 1.213 (with a t-statistics of 26.89). These error components indicate that there are common unobserved factors that predispose children to participate in specific activity purposes and in specific company type arrangements. For instance, a child predisposed to shopping has a high baseline preference for all company type arrangements within the shopping category, and a child predisposed to participate alone tends to do so regardless of activity purpose.

\subsubsection{Likelihood-Based Measures of Fit}

The log-likelihood value at convergence of the final model is -11327 . The corresponding value for the model with only the constants in the baseline preference and the satiation parameters is -11959. The likelihood ratio test for testing the presence of exogenous variable effects on baseline preference and error components is 1264 , which is substantially larger than the critical

\footnotetext{
${ }^{13}$ There was no statistically significant variation in $\alpha_{1}$ based on observed child-associated characteristics $y_{1}$. The reader will also note that there are no $\alpha$ terms appearing for the out-of-home alternatives, because they are all implicitly held to 0 . This is because of empirical identification considerations that make it difficult to estimate both $\alpha$ and $\gamma$ simultaneously (for a detailed discussion, see Bhat, 2007).

${ }^{14}$ There were no statistically significant variations in $\gamma_{k}$ based on child-related characteristics $\omega_{k}$.
} 
chi-square value with 59 degrees of freedom at any reasonable level of significance. This clearly indicates the value of the model estimated in this paper to predict the discretionary time use of children based on child demographics, parent demographics, household demographics, household location variables and day of week/seasonal effects.

\section{CONCLUSIONS}

The focus of this paper is on the discretionary activity time-use of children over a weekend day, classified by the type of intra-household and inter-household accompanying arrangement. The data used in the analysis is drawn from the 2002 Child Development Supplement (CDS) to the U.S. Panel Study of Income Dynamics. The CDS provides extensive information on the daily activity-travel participations of a sample of U.S. children, and is ideally suited for the context of the current study. Several categories of explanatory variables are considered in the analysis, including child demographics, parent demographics, household demographics, household location variables, and day of week/season of year effects.

There are several interesting findings from the analysis. For instance, the results show gender effects in company type for participation in out-of-home discretionary (OHD) activities, with male children more likely to participate with their fathers than female children. The child's race also has a bearing on OHD time-use, with African-American children less likely to participate in health-enhancing active recreation pursuits. The underlying reason for the race differences need to be studied carefully, so that any inequities in infrastructure provision can be identified and addressed. Among parents' demographic variables, the presence of well educated parents appears to provide a balance in children's activity participation relative to gender stereotypes. Household demographics, location variables, day of week, and season of the year also have an impact on the type of discretionary activity pursuits and with whom.

The model estimated in this paper can be used to estimate changes in the time use patterns of children due to changes in explanatory variables. For instance, U.S. Census Bureau (2004) projections suggest a decrease in the Caucasian-American fraction of the U.S. population

over the next few decades, with a concomitant increase in African-American, Asian, and Hispanic populations. This racial composition change, according to our empirical analysis, implies a decrease in children's active recreation pursuits, which, in turn, can result in serious health problems (both physical and emotional) for children as well as adults. Appropriate 
policies to encourage active lifestyles through awareness campaigns and provision of more active recreation opportunities are needed to counteract these trends.

In addition to changes in the race composition, the U.S. Census Bureau (2004) indicates that the country's population is aging. The results of our analysis show that children with older parents are more likely to participate in OHD activities with their parents than children with younger parents. Consequently, transportation planners need to better understand the role of intra-household interactions in activity and travel behavior to inform land-use and transportation policy-making.

In addition to the implications of the research results for travel and activity behavior, the model developed in the paper can be used as part of activity-based travel frameworks for forecasting purposes. For example, in the Comprehensive Econometric Microsimulator for Daily Activity-travel Patterns (CEMDAP; see Pinjari et al., 2006), one of the modules of the activity generation stage corresponds to the prediction of children's discretionary activity participations and the accompanying individuals. The model in this paper can readily be integrated for this purpose.

In summary, the model estimated in this study can be used to better understand children's activity participation and time-use decisions, and the interactions of children with other individuals. Our findings indicate substantial linkages between children's activity participations and those of household and non-household members. These interactions need to be recognized within the framework of activity-based travel modeling for reliable transportation policy analysis and accurate travel forecasting. In this regard, the study emphasizes the need to collect information on the social context of activity participation in activity-travel surveys. The study also contributes to the sociological and public health fields by examining the factors affecting children's discretionary activity-time use decisions. Thus, the results obtained can provide valuable insights for comprehensive and reliable transportation studies, and urban and societal policy analyses.

\section{ACKNOWLEDGEMENTS}

The authors appreciate the valuable comments of four anonymous reviewers and Martin Richards on an earlier version of the paper. The authors would like to thank Rachel Copperman 
for her help with the data. The first author would like to dedicate her part of the research efforts to her beloved family. 


\section{REFERENCES}

Arentze, T., and Timmermans, H. (2004) Multistate Supernetwork Approach to Modeling MultiActivity, Multimodal Trip Chains. International Journal of Geographical Information Science, 18(7): 631-651.

Axhausen, K.W. (2005) Social Networks and Travel: Some Hypothesis. In Donaghy, K. (ed.) Social Aspects of Sustainable Transport: Transatlantic Perspectives, Ashgate, Aldershot.

Bhat, C.R. (2003) Simulation Estimation of Mixed Discrete Choice Models Using Randomized and Scrambled Halton Sequences. Transportation Research Part B, 37(9): 837-855.

Bhat, C.R. (2005) A Multiple Discrete-Continuous Extreme Value Model: Formulation and Application to Discretionary Time-Use Decisions. Transportation Research Part B, 39(8): 679-707.

Bhat, C.R. (2007) The Multiple Discrete-Continuous Extreme Value (MDCEV) Model: Role of Utility Function Parameters, Identification Considerations, and Model Extensions. Forthcoming, Transportation Research Part B.

Bhat, C.R., and Gossen, R. (2004) A Mixed Multinomial Logit Model Analysis of Weekend Recreational Episode Type Choice. Transportation Research Part B, 38(9): 767-787.

Bhat, C.R., and Koppelman, F.S. (1999) A Retrospective and Prospective Survey of Time-Use Research. Transportation, 26(2): 119-139.

Bhat, C.R., and Pendyala, R.M. (2005) Modeling Intra-Household Interactions and Group Decision-Making. Transportation, 32(5): 443-448.

Bhat, C.R., Srinivasan, S., and Sen, S. (2006) A Joint Model for the Perfect and Imperfect Substitute Goods Case: Application to Activity Time-Use Decisions. Transportation Research Part B, 40(10): 827-850.

Bianchi, S.M., and Robinson, J. (1997) What Did You Do Today? Children's Use of Time, Family Composition, and the Acquisition of Social Capital. Journal of Marriage and Family, 59(2): 332-344.

Bradley, M., and Vovsha, P. (2005) A Model for Joint Choice of Daily Activity Pattern Types of Household Members. Transportation, 32(5): 545-571.

Center for Disease Control (CDC) (2005) Positive Parenting Tips for Healthy Child Development. Child Development. Online at http://www.cdc.gov/ncbddd/child/documents/6-8YearOldsPositiveParenting.pdf

Center for Disease Control (CDC) (2006) Youth Risk Behavior Surveillance-United States, 2005. Morbidity and Mortality Weekly Report, 55: SS-5. 
Cooksey, E.C., and Fondell, M.M. (1996) Spending Time with his Kids: Effects of Family Structure on Fathers' and Children's Lives. Journal of Marriage and Family, 58(3): 693707.

Copperman, R., and Bhat, C.R. (2007a) An Exploratory Analysis of Children's Daily Time-Use and Activity Patterns Using the Child Development Supplement (CDS) to the U.S. Panel Study of Income Dynamics (PSID). Forthcoming, Transportation Research Record.

Copperman, R., and Bhat, C.R. (2007b) An Analysis of the Determinants of Children's Weekend Activity Participation. Transportation, 34(1): 67-87.

Eccles, J.S. (1999) The Development of Children Ages 6 to 14. The Future of Children, 9(2): 3044.

Gliebe, J.P., and Koppelman, F.S. (2005) Modeling Household Activity-Travel Interactions as Parallel Constrained Choices. Transportation, 32(5): 449-471.

Golob, T.F. and McNally, G.M. (1997) A Model of Activity Participation and Travel Interactions between Household Heads. Transportation Research Part B, 31(3): 177-194.

Goulias, K.G., and Kim, T.G. (2005) An Analysis of Activity Type Classification and Issues Related to the With Whom and For Whom Questions of an Activity Diary. In Timmermans, H.J.P. (ed.) Progress in Activity-Based Analysis, Elsevier, Oxford, England.

Hofferth, S.L., and Jankuniene, J. (2001) Life after School. Association for Supervision and Curriculum Development, pp. 19-23.

Hofferth, S.L., and Sandberg, J. (2001) How American Children Spend their Time. Journal of Marriage and Family, 63(2): 295-308.

Hofferth, S.L. (2003) Race/Ethnic Differences in Father Involvement in Two-Parent Families: Culture, Context, or Economy? Journal of Family Issues, 24(2): 185-216.

Kato, H., and Mataumoto, M. (2006) Joint Resource Allocation Model of Household Consisting of a Husband, a Wife and a Child for Non-work Activities: Comparative Analysis of Tokyo and Toyama, Japan. Presented at the $6^{\text {th }}$ Swiss Transport Research Conference, Monte Verita, Ascona.

Kitamura, R. (1983) Serve Passenger Trips as a Determinant of Travel Behaviour. In Carpenter, S., and Jones, P.M. (eds.) Recent Advances in Travel Demand, Gower, Aldershot, UK.

Kohl III, H.W., and Hobbs, K.E. (1998) Development of Physical Activity Behavior Among Children and Adolescents. Pediatric, 101(3): 549-554. 
Larson, R.W. and Verma, S. (1999) How Children and Adolescents Spend Time Across the World: Work, Play, and Developmental Opportunities. Physiological Bulletin, 125(6): 701-736.

Lockwood, A., Srinivasan, S., and Bhat, C.R. (2005) An Exploratory Analysis of Weekend Activity Patterns in the San Francisco Bay Area, Transportation Research Record, 1926: 70-78.

Parsons Brinckerhoff Quade and Douglas, Inc. (2000) Comparative Analysis, Weekday and Weekend Travel with NPTS Integration for the RT-HIS: Regional Travel-Household Interview Survey. Prepared for the New York Metropolitan Transportation Council and the North Jersey Transportation Planning Authority, Inc.

Pendyala, R.M., and Goulias, K.G. (2002) Time Use and Activity Perspectives in Travel Behavior Research. Transportation, 29(1): 1-4.

Pinjari, A., Eluru, N., Copperman, R. Sener, I.N., Guo, J.Y., Srinivasan, S., and Bhat, C.R. (2006) Activity-Based Travel-Demand Analysis for Metropolitan Areas in Texas: CEMDAP Models, Framework, Software Architecture and Application Results, Report 4080-8, prepared for the Texas Department of Transportation, October.

Pribyl, O., and Goulias, K.G. (2005) Simulation of Daily Activity Patterns. In Timmermans, H.J.P. (ed.) Progress in Activity-Based Analysis, Elsevier, Oxford, England.

Sandberg, J.F., and Hofferth, S. (2001) Changes in Children's Time with Parents: United States, 1981-1997. Demography, 38(3): 423-436.

Scott, D.M., and Kanaroglou, P.S. (2002) An Activity-Episode Generation Model that Captures Interactions Between Household Heads: Development and Empirical Analysis. Transportation Research Part B, 36(10): 875-896.

Shann, M.H. (2001) Students' Use of Time Outside of School: A Case for After School Programs for Urban Middle School Youth. The Urban Review, 33(4): 339-355.

Srinivasan, K.K., and Athuru, S.R. (2005) Analysis of Within-Household Effects and Between Household Differences in Maintenance Activity Allocation. Transportation, 32(5): 495521.

Srinivasan, S., and Bhat, C.R. (2005) Modeling Household Interactions in Daily In-Home and Out-of-Home Maintenance Activity Participation. Transportation, 32(5): 523-544.

Srinivasan, S., and Bhat, C.R. (2006a) An Explanatory Analysis of Joint Activity Participation Characteristics Using the American Time Use Survey. Technical Paper, Department of Civil Engineering, The University of Texas at Austin, July. 
Srinivasan, S., and Bhat, C.R. (2006b) Companionship for Leisure Activities: An Empirical Analysis Using the American Time Use Survey. Presented at the Innovations in Travel Demand Modeling Conference, Austin, Texas.

Transportation Research Board and Institute of Medicine (2005) Does the Built Environment Influence Physical Activity? Examining the Evidence. TRB Special Report 282.

United Nations (2000) The World Programme of Action for Youth on Leisure-Time Activities. Online at http://www.un.org/events/youth98/backinfo/ywpa2000.htm.

U.S. Bureau of Census (2004) U.S. Interim Projections by Age, Sex, race, and Hispanic Origin. Online at http://www.census.gov/ipc/www/usinterimproj/

Zhang, J., Fujiwara, A., Timmermans, H.J.P., and Borgers, A. (2004) Methodology for Modeling Household Time Allocation Behavior. Presented at the EIRASS Conference in Advances in Activity Based Approaches, Maastricht, The Netherlands. 


\section{LIST OF TABLES}

Table 1. Descriptive Statistics of Activity Purpose Participation

Table 2. Descriptive Statistics of Companionship Type for Out-of-Home Discretionary Activity Purposes

Table 3. Distribution of Participation in Out-of-Home Discretionary Activities by Purpose and Company Type

Table 4. MDCEV Model Results

Table 5. Satiation Parameters - $\gamma$ 
Table 1. Descriptive Statistics of Activity Purpose Participation

\begin{tabular}{|c|c|c|c|c|}
\hline \multirow{2}{*}{ Activity Purpose } & \multirow{2}{*}{$\begin{array}{c}\text { Total number }(\%) \\
\text { of individuals } \\
\text { participating }\end{array}$} & \multirow{2}{*}{$\begin{array}{l}\text { Mean duration of } \\
\text { participation } \\
(\text { mins })\end{array}$} & \multicolumn{2}{|c|}{$\begin{array}{l}\text { Number of individuals (\% of total number participating) } \\
\text { who participate.... }\end{array}$} \\
\hline & & & Only in activity purpose & $\begin{array}{l}\text { In the activity purpose and } \\
\text { other activity purposes }\end{array}$ \\
\hline IH leisure & $1574(100 \%)$ & 457 & $68 \quad(4 \%)$ & $1506(96 \%)$ \\
\hline Shopping & $533(34 \%)$ & 75 & $115(22 \%)$ & $418 \quad(78 \%)$ \\
\hline Social & $790 \quad(50 \%)$ & 81 & $205(26 \%)$ & $585 \quad(74 \%)$ \\
\hline Meals & $641 \quad(41 \%)$ & 38 & $27(4 \%)$ & $614(96 \%)$ \\
\hline Passive recreation & $722(46 \%)$ & 173 & $117(16 \%)$ & $605(84 \%)$ \\
\hline Active recreation & $390(25 \%)$ & 134 & $71 \quad(18 \%)$ & $319(82 \%)$ \\
\hline
\end{tabular}


Table 2. Descriptive Statistics of Companionship Type for Out-of-Home Discretionary Activity Purposes

\begin{tabular}{|c|c|c|c|c|}
\hline \multirow{2}{*}{ Companionship Type } & \multirow{2}{*}{$\begin{array}{c}\text { Total number }\left(\%^{*}\right) \\
\text { of individuals } \\
\text { participating }\end{array}$} & \multirow{2}{*}{$\begin{array}{l}\text { Mean duration of } \\
\text { participation (mins) }\end{array}$} & \multicolumn{2}{|c|}{$\begin{array}{c}\text { Number of individuals (\% of total number } \\
\text { participating) who participate... }\end{array}$} \\
\hline & & & Only with... & $\begin{array}{l}\text { With the companion and } \\
\text { other companionship types }\end{array}$ \\
\hline Alone & $190(13 \%)$ & 124 & $34 \quad(18 \%)$ & $156(82 \%)$ \\
\hline Mother & $184(12 \%)$ & 81 & $49 \quad(27 \%)$ & $135(73 \%)$ \\
\hline Father & $92 \quad(6 \%)$ & 106 & $18(20 \%)$ & $74 \quad(80 \%)$ \\
\hline Parents & $69 \quad(5 \%)$ & 76 & $19(28 \%)$ & $50 \quad(72 \%)$ \\
\hline No parents & $981 \quad(65 \%)$ & 183 & $445 \quad(45 \%)$ & $536(55 \%)$ \\
\hline Parents and others & $766 \quad(51 \%)$ & 96 & $305 \quad(40 \%)$ & $461 \quad(60 \%)$ \\
\hline
\end{tabular}

* Percentages are out of individuals who participate in at least one out-of-home discretionary activity; i.e., out of 1506. 
Table 3. Distribution of Participation in Out-of-Home Discretionary Activities by Purpose and Company Type

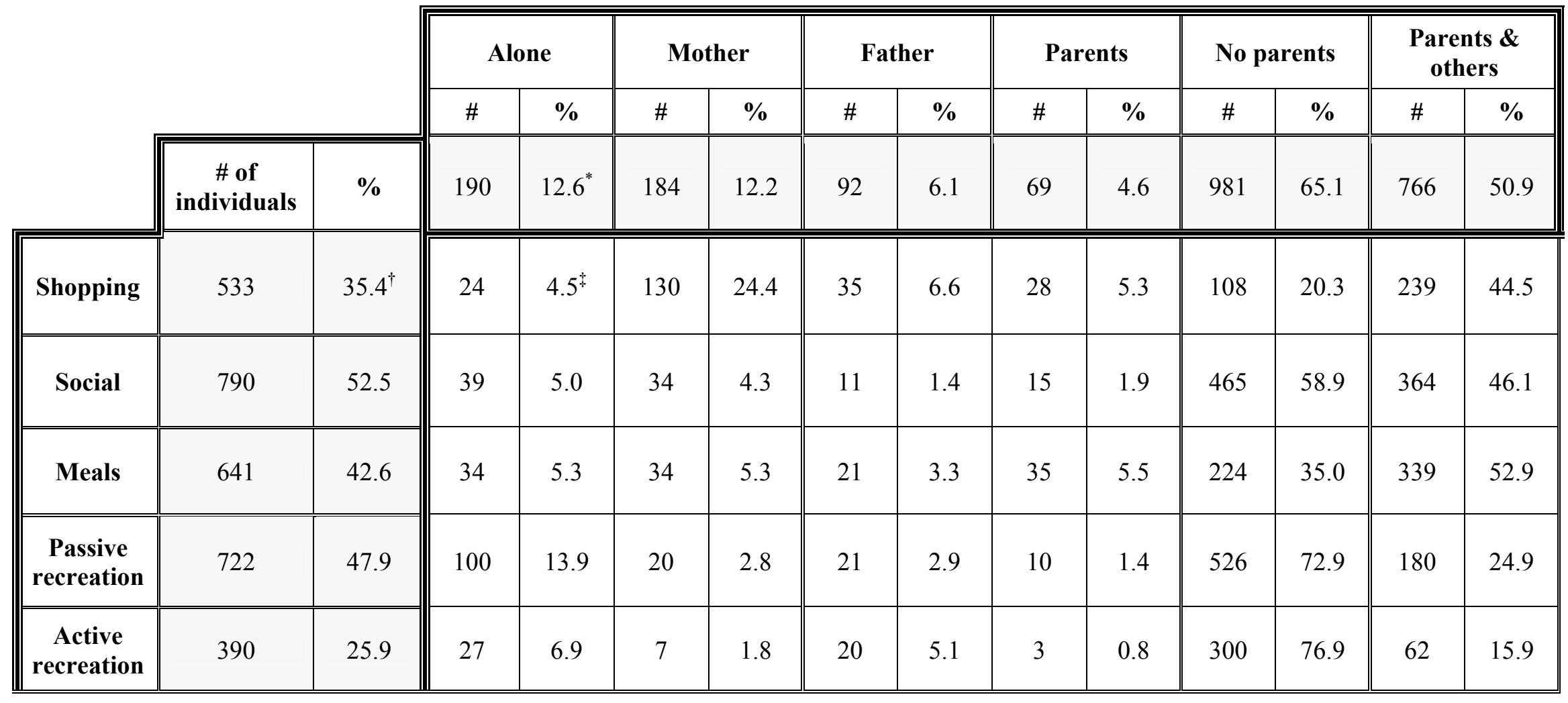

${ }^{*}$ and ${ }^{\dagger}$ Percentages are based on the number of individuals who participate in at least one out-of-home discretionary activity during the survey day; i.e., out of 1506 individuals.

${ }^{\ddagger}$ Percentages are based on total number of individuals participating in row activity type [(24/533)x $\left.100=4.5 \%\right]$. 
Table 4. MDCEV Model Results

\begin{tabular}{|c|c|c|c|c|c|c|c|c|c|c|}
\hline \multirow{3}{*}{$\begin{array}{c}\text { Child } \\
\text { Demographics }\end{array}$} & \multirow{2}{*}{\multicolumn{2}{|c|}{$\begin{array}{c}\text { Child's age } \\
\left(\mathbf{x 1 0 ^ { - 1 } )}\right. \\
\text { Continuous } \\
\text { Variable } \\
\end{array}$}} & \multirow{2}{*}{\multicolumn{2}{|c|}{ Male }} & \multicolumn{4}{|c|}{ Child's Race } & \multirow{2}{*}{\multicolumn{2}{|c|}{$\begin{array}{l}\text { Physically } \\
\text { Challenged }\end{array}$}} \\
\hline & & & & & \multicolumn{2}{|c|}{$\begin{array}{l}\text { Caucasian- } \\
\text { American }\end{array}$} & \multicolumn{2}{|c|}{$\begin{array}{c}\text { African- } \\
\text { American }\end{array}$} & & \\
\hline & Est. & t-stat & Est. & t-stat & Est. & t-stat & Est. & t-stat & Est. & t-stat \\
\hline Activity Purpose Dimension & & & & & & & & & & \\
\hline IH leisure & - & - & - & - & - & - & - & - & - & - \\
\hline Shopping & - & - & -0.292 & -2.88 & -0.274 & -1.93 & -0.489 & -3.35 & - & - \\
\hline Social & - & - & - & - & - & - & - & - & - & - \\
\hline Meals & - & - & - & - & - & - & -0.273 & -2.32 & - & - \\
\hline Passive recreation & -0.821 & -5.93 & - & - & 0.331 & 3.08 & - & - & - & - \\
\hline Active recreation & - & - & 0.294 & 1.47 & 0.821 & 5.91 & - & - & - & - \\
\hline Company Type Dimension & & & & & & & & & & \\
\hline Alone & - & - & - & - & - & - & - & - & - & - \\
\hline Mother & -0.827 & -2.61 & -0.474 & -2.59 & 0.222 & 1.13 & - & - & - & - \\
\hline Father & - & - & 0.262 & 1.03 & - & - & -1.591 & -2.92 & - & - \\
\hline Parents & - & - & - & - & - & - & - & - & - & - \\
\hline No parents & 1.128 & 6.70 & - & - & - & - & 0.518 & 3.87 & -0.421 & -1.58 \\
\hline Parents and others & -0.625 & -3.63 & - & - & - & - & - & - & - & - \\
\hline Purpose-Company Type Interaction & & & & & & & & & & \\
\hline Social with mother & - & - & - & - & - & - & - & - & - & - \\
\hline Social with no parents & - & - & - & - & 0.283 & 1.97 & - & - & - & - \\
\hline Meals with no parents & - & - & - & - & 0.486 & 2.64 & - & - & - & - \\
\hline Passive recreation with no parents & - & - & - & - & - & - & - & - & - & - \\
\hline Active recreation with no parents & - & - & 0.495 & 2.08 & - & - & - & - & - & - \\
\hline
\end{tabular}


Table 4. (continued) MDCEV Model Results

\begin{tabular}{|c|c|c|c|c|c|c|c|c|c|c|}
\hline \multirow{3}{*}{$\begin{array}{c}\text { Parent } \\
\text { Demographics }\end{array}$} & \multicolumn{4}{|c|}{$\begin{array}{c}\text { Age-related } \\
\text { Continuous Variables }\end{array}$} & \multirow{2}{*}{\multicolumn{2}{|c|}{$\begin{array}{c}\text { Employment } \\
\text { Variables } \\
\text { Only Father } \\
\text { Employed }\end{array}$}} & \multicolumn{4}{|c|}{$\begin{array}{c}\text { Education-related } \\
\text { Variables }\end{array}$} \\
\hline & \multicolumn{2}{|c|}{$\begin{array}{l}\text { Mother age } \\
\left(\mathbf{x 1 0}^{-1}\right)\end{array}$} & \multicolumn{2}{|c|}{$\begin{array}{c}\text { Father age } \\
\left(\mathrm{x10}^{-1}\right)\end{array}$} & & & \multicolumn{2}{|c|}{$\begin{array}{c}\text { Mother Bachelor's } \\
\text { or more }\end{array}$} & \multicolumn{2}{|c|}{$\begin{array}{l}\text { Father Bachelor's } \\
\text { or more }\end{array}$} \\
\hline & Est. & t-stat & Est. & t-stat & Est. & t-stat & Est. & t-stat & Est. & t-stat \\
\hline Activity Purpose Dimension & & & & & & & & & & \\
\hline IH leisure & - & - & - & - & - & - & - & - & - & - \\
\hline Shopping & - & - & - & - & - & - & -0.327 & -3.09 & - & - \\
\hline Social & - & - & - & - & - & - & - & - & 0.310 & 3.56 \\
\hline Meals & - & - & - & - & - & - & - & - & - & - \\
\hline Passive recreation & - & - & - & - & - & - & - & - & - & - \\
\hline Active recreation & - & - & - & - & - & - & - & - & - & - \\
\hline Company Type Dimension & & & & & & & & & & \\
\hline Alone & - & - & - & - & - & - & - & - & - & - \\
\hline Mother & 0.165 & 1.12 & - & - & -0.551 & 2.75 & 0.641 & 3.13 & - & - \\
\hline Father & - & - & 0.243 & 1.50 & - & - & - & - & - & - \\
\hline Parents & - & - & - & - & - & - & - & - & - & - \\
\hline No parents & - & - & - & - & - & - & - & - & - & - \\
\hline Parents and others & - & - & - & - & - & - & 0.366 & 3.44 & - & - \\
\hline Purpose-Company Type Interactions & & & & & & & & & & \\
\hline Social with mother & - & - & - & - & - & - & -1.193 & -3.06 & - & - \\
\hline Social with no parents & - & - & - & - & - & - & - & - & - & - \\
\hline Meals with no parents & - & - & - & - & - & - & - & - & - & - \\
\hline Passive recreation with no parents & - & - & - & - & - & - & - & - & - & - \\
\hline Active recreation with no parents & - & - & - & - & - & - & - & - & - & - \\
\hline
\end{tabular}


Table 4. (continued) MDCEV Model Results

\begin{tabular}{|c|c|c|c|c|c|c|c|c|}
\hline \multirow{2}{*}{$\begin{array}{c}\text { Household } \\
\text { Demographics }\end{array}$} & \multicolumn{2}{|c|}{$\begin{array}{c}\# \text { of } \\
\text { adults }\end{array}$} & \multicolumn{2}{|c|}{$\begin{array}{c}\text { \# of } \\
\text { children }\end{array}$} & \multicolumn{2}{|c|}{$\begin{array}{l}\text { Single Parent } \\
\text { Family }\end{array}$} & \multicolumn{2}{|c|}{$\begin{array}{l}\text { Low } \\
\text { Income } \\
(<25 K)\end{array}$} \\
\hline & Est. & t-stat & Est. & t-stat & Est. & t-stat & Est. & t-stat \\
\hline$\underline{\text { Activity Purpose Dimension }}$ & & & & & & & & \\
\hline IH leisure & - & - & - & - & - & - & 0.252 & 2.66 \\
\hline Shopping & - & - & - & - & - & - & - & - \\
\hline Social & - & - & - & - & - & - & - & - \\
\hline Meals & - & - & -0.154 & -3.08 & - & - & - & - \\
\hline Passive recreation & -0.159 & -1.99 & -0.185 & -3.92 & - & - & - & - \\
\hline Active recreation & - & - & - & - & - & - & - & - \\
\hline Company Type Dimension & & & & & & & & \\
\hline Alone & - & - & - & - & - & - & - & - \\
\hline Mother & - & - & -0.765 & -6.50 & - & - & - & - \\
\hline Father & - & - & - & - & 1.242 & 1.89 & - & - \\
\hline Parents & -0.345 & -1.14 & -1.080 & -5.56 & - & - & - & - \\
\hline No parents & - & - & 0.102 & 1.92 & 0.266 & 1.99 & - & - \\
\hline Parents and others & - & - & 0.218 & 3.89 & - & - & - & - \\
\hline$\underline{\text { Purpose-Company Type Interactions }}$ & & & & & & & & \\
\hline Social with mother & - & - & - & - & - & - & - & - \\
\hline Social with no parents & - & - & - & - & - & - & - & - \\
\hline Meals with no parents & - & - & - & - & - & - & - & - \\
\hline Passive recreation with no parents & - & - & - & - & -0.240 & -1.57 & - & - \\
\hline Active recreation with no parents & - & - & - & - & - & - & - & - \\
\hline
\end{tabular}


Table 4. (continued) MDCEV Model Results

\begin{tabular}{|c|c|c|c|c|c|c|c|c|c|c|c|c|c|c|}
\hline \multirow{3}{*}{$\begin{array}{c}\text { Household Location Variables } \\
\text { and Day of Week } \\
\text { \& Seasonal Effects }\end{array}$} & \multirow{2}{*}{\multicolumn{2}{|c|}{$\begin{array}{c}\begin{array}{c}\text { Zonal } \\
\text { Location } \\
\text { Variables }\end{array} \\
\text { Urban }\end{array}$}} & \multicolumn{6}{|c|}{ Regional Location Variables } & \multirow{2}{*}{\multicolumn{2}{|c|}{$\begin{array}{c}\text { Day of Week } \\
\text { Sunday }\end{array}$}} & \multicolumn{4}{|c|}{ Seasonal Effects } \\
\hline & & & \multicolumn{2}{|c|}{ Northeast } & \multicolumn{2}{|c|}{ Northcentral } & \multicolumn{2}{|c|}{ West } & & & \multicolumn{2}{|c|}{ Fall } & \multicolumn{2}{|c|}{ Winter } \\
\hline & Est. & t-stat & Est. & t-stat & Est. & t-stat & Est. & t-stat & Est. & t-stat & Est. & t-stat & Est. & t-stat \\
\hline Activity Purpose Dimension & & & & & & & & & & & & & & \\
\hline IH leisure & - & - & 0.146 & 1.22 & 0.200 & 2.06 & - & - & 0.197 & 2.86 & - & - & - & - \\
\hline Shopping & 0.451 & 4.45 & - & - & - & - & - & - & - & - & - & - & - & - \\
\hline Social & - & - & - & - & - & - & - & - & 0.939 & 11.63 & - & - & - & - \\
\hline Meals & - & - & - & - & - & - & - & - & - & - & - & - & - & - \\
\hline Passive recreation & - & - & - & - & - & - & - & - & - & - & & & & \\
\hline Active recreation & 0.300 & 2.61 & - & - & - & - & - & - & - & - & -0.654 & -3.64 & -0.729 & -4.67 \\
\hline Company Type Dimension & & & & & & & & & & & & & & \\
\hline Alone & 0.292 & 1.66 & -0.487 & -1.81 & - & - & -0.641 & -2.76 & -0.329 & -2.24 & - & - & - & - \\
\hline Mother & - & - & - & - & - & - & - & - & - & - & - & - & - & - \\
\hline Father & - & - & - & - & - & - & - & - & - & - & - & - & - & - \\
\hline Parents & - & - & - & - & - & - & - & - & - & - & - & - & - & - \\
\hline No parents & - & - & - & - & - & - & - & - & - & - & 0.371 & 2.11 & 0.154 & 1.00 \\
\hline Parents and others & - & - & - & - & - & - & - & - & - & - & - & - & - & - \\
\hline Purpose-Company Type Interaction & & & & & & & & & & & & & & \\
\hline Social with mother & - & - & - & - & - & - & - & - & - & - & - & - & - & - \\
\hline Social with no parents & - & - & -0.314 & -1.83 & - & - & - & - & - & - & - & - & - & - \\
\hline Meals with no parents & - & - & - & - & - & - & -0.470 & -2.30 & - & - & - & - & - & - \\
\hline Passive recreation with no parents & - & - & - & - & 0.381 & 3.01 & - & - & - & - & - & - & - & - \\
\hline Active recreation with no parents & - & - & - & - & - & - & - & - & - & - & - & - & - & - \\
\hline
\end{tabular}


Table 4. (continued) MDCEV Model Results

\begin{tabular}{|c|c|c|c|c|c|c|}
\hline \multirow{2}{*}{$\begin{array}{c}\text { Baseline Preference } \\
\text { Constants }\end{array}$} & \multirow{2}{*}{$\begin{array}{l}\text { In-home } \\
\text { leisure }\end{array}$} & \multicolumn{5}{|c|}{ Out-of-home Leisure Constants (t-statistics) } \\
\hline & & Shopping & Social & Meals & $\begin{array}{l}\text { Passive } \\
\text { recreation }\end{array}$ & $\begin{array}{l}\text { Active } \\
\text { recreation }\end{array}$ \\
\hline Alone & - & $\begin{array}{c}-4.756 \\
(-15.73)\end{array}$ & $\begin{array}{l}-5.183 \\
(-20.89)\end{array}$ & $\begin{array}{l}-4.276 \\
(-16.03)\end{array}$ & $\begin{array}{l}-2.279 \\
(-7.66)\end{array}$ & $\begin{array}{l}-5.151 \\
(-15.77)\end{array}$ \\
\hline Mother & - & $\begin{array}{l}-1.208 \\
(-1.99)\end{array}$ & $\begin{array}{l}-3.053 \\
(-4.89)\end{array}$ & $\begin{array}{l}-2.685 \\
(-4.34)\end{array}$ & $\begin{array}{l}-2.467 \\
(-3.75)\end{array}$ & $\begin{array}{l}-2.443 \\
(-2.35)\end{array}$ \\
\hline Father & - & $\begin{array}{l}-5.360 \\
(-7.47)\end{array}$ & $\begin{array}{l}-7.649 \\
(-10.03)\end{array}$ & $\begin{array}{l}-6.050 \\
(-8.14)\end{array}$ & $\begin{array}{l}-5.338 \\
(-6.90)\end{array}$ & $\begin{array}{l}-6.573 \\
(-8.67)\end{array}$ \\
\hline Parents & - & $\begin{array}{l}-1.663 \\
(-2.02)\end{array}$ & $\begin{array}{l}-3.502 \\
(-4.21)\end{array}$ & $\begin{array}{l}-1.450 \\
(-1.81)\end{array}$ & $\begin{array}{l}-1.919 \\
(-2.21)\end{array}$ & $\begin{array}{l}-2.443 \\
(-2.35)\end{array}$ \\
\hline No parents & - & $\begin{array}{c}-4.900 \\
(-14.58)\end{array}$ & $\begin{array}{l}-4.185 \\
(-13.57)\end{array}$ & $\begin{array}{l}-4.055 \\
(-11.98)\end{array}$ & $\begin{array}{l}-1.878 \\
(-5.29)\end{array}$ & $\begin{array}{l}-4.487 \\
(-13.16)\end{array}$ \\
\hline Parents and others & - & $\begin{array}{l}-2.281 \\
(-7.98)\end{array}$ & $\begin{array}{l}-2.791 \\
(-10.91)\end{array}$ & $\begin{array}{l}-1.711 \\
(-6.52)\end{array}$ & $\begin{array}{l}-1.683 \\
(-5.09)\end{array}$ & $\begin{array}{c}-4.369 \\
(-12.65)\end{array}$ \\
\hline
\end{tabular}

* In-home leisure is the base category for the baseline preference constants. 
Table 5. Satiation Parameters - $\gamma$

\begin{tabular}{|c|c|c|}
\hline Activity Type & Parameter $(\gamma)$ & t-statistic \\
\hline Shopping alone & 0.186 & 3.05 \\
\hline Shopping with mother & 0.172 & 6.54 \\
\hline Shopping with father & 0.151 & 3.37 \\
\hline Shopping with parents & 0.170 & 3.12 \\
\hline Shopping with no parents & 0.222 & 6.25 \\
\hline Shopping with parents and others & 0.200 & 8.94 \\
\hline Social alone & 0.352 & 3.83 \\
\hline Social with mother & 0.300 & 3.51 \\
\hline Social with father & 0.182 & 1.99 \\
\hline Social with parents & 0.401 & 2.20 \\
\hline Social with no parents & 0.292 & 12.12 \\
\hline Social with parents and others & 0.270 & 11.25 \\
\hline Meals alone & 0.236 & 3.62 \\
\hline Meals with mother & 0.222 & 3.53 \\
\hline Meals with father & 0.260 & 2.40 \\
\hline Meals with parents & 0.168 & 3.53 \\
\hline Meals with no parents & 0.136 & 9.21 \\
\hline Meals with parents and others & 0.123 & 11.06 \\
\hline Passive recreation alone & 0.884 & 5.16 \\
\hline Passive recreation with mother & 0.410 & 2.58 \\
\hline Passive recreation with father & 0.446 & 2.08 \\
\hline Passive recreation with parents & 0.851 & 1.56 \\
\hline Passive recreation with no parents & 0.674 & 11.53 \\
\hline Passive recreation with parents and others & 0.474 & 7.44 \\
\hline Active recreation alone & 0.484 & 2.79 \\
\hline Active recreation with mother & 0.769 & 1.54 \\
\hline Active recreation with father & 0.858 & 2.06 \\
\hline Active recreation with parents & 0.769 & 1.54 \\
\hline Active recreation with no parents & 0.483 & 9.04 \\
\hline Active recreation with parents and others & 0.356 & 4.51 \\
\hline
\end{tabular}

